\title{
Análise do comportamento de estacas escavadas, instrumentadas, com e sem anéis em solo sedimentar.
}

\section{Izabella Bigosinshi Corrêa*, Paulo José Rocha de Albuquerque (orientador).}

\section{Resumo}

Esta pesquisa teve como objetivo avaliar a capacidade de carga de estacas escavadas com anéis ao longo do fuste. Duas estacas escavadas, uma com anéis e uma convencional, foram analisadas a partir de provas de carga estática instrumentadas (PCE) e métodos de previsão de capacidade. Os resultados mostram ganho de $72 \%$ na capacidade à compressão para a estaca com anéis em relação à convencional.

\section{Palavras-chave:}

Estaca escavada, Provas de carga, Capacidade de carga.

\section{Introdução}

As estacas escavadas possuem capacidade de carga reduzida em relação às demais. Assim, a execução de anéis no fuste, para ganho de capacidade, é de interesse da comunidade técnica. A fim de avaliar o comportamento das estacas com anéis foram realizadas PCE, permitindo conhecer sua capacidade e distribuição da resistência em relação à estaca escavada convencional.

\section{Resultados e Discussão}

As estacas ensaiadas são apresentadas na Fig. 1.

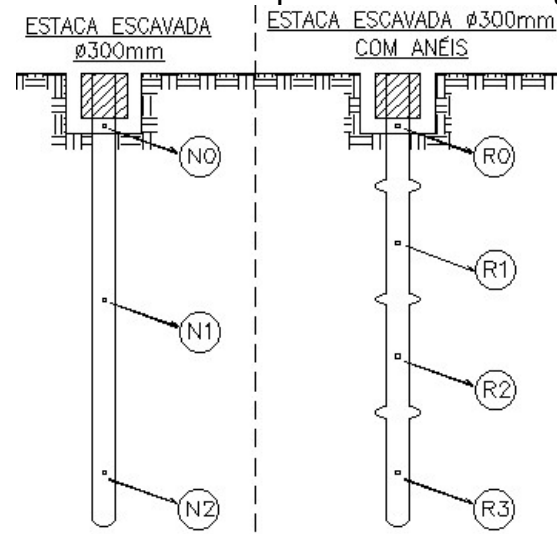

Figura 1. Estacas e níveis de instrumentação.

A partir dos dados das PCE, obteve-se as curvas de carga vs. recalque e verificou-se que o recalque ocorre em menor escala para a estaca com anéis (Fig. 2).

Carga Aplicada $(\mathbf{k N}) \multimap-$ Estaca com anéis $\longrightarrow$ Estaca de referência

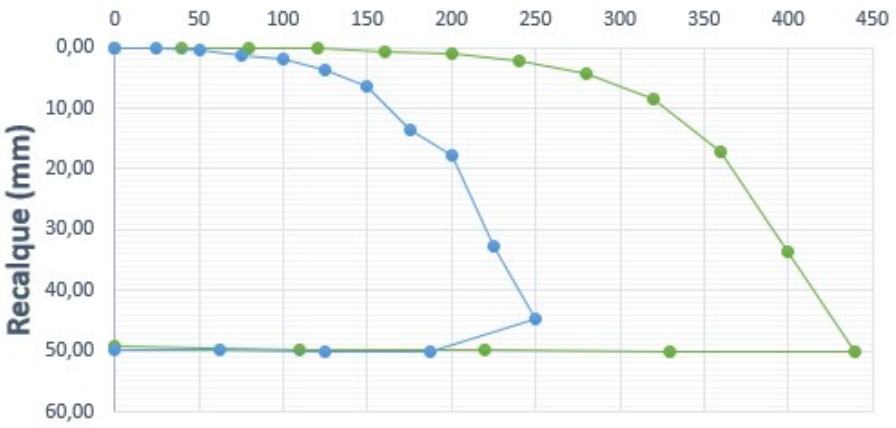

Figura 2. Curvas de carga vs. recalque.

As cargas de ruptura obtidas foram: $251 \mathrm{kN}$ para a estaca convencional e $433 \mathrm{kN}$ para a estaca com anéis (72\% maior do que para a estaca convencional).

A partir da instrumentação, foi determinado o atrito lateral das estacas ensaiadas. É possível observar que a resistência lateral da estaca com anéis é maior, justificando o ganho de capacidade de carga (Fig. 3).

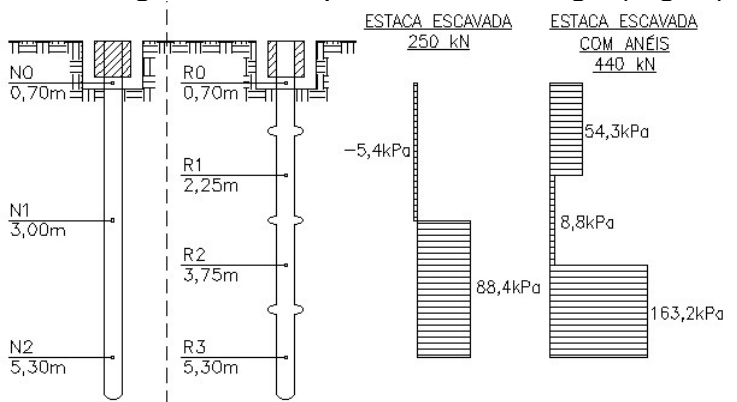

Figura 3. Atrito lateral para as estacas com e sem anéis.

A capacidade de carga das estacas foi estudada por meio de diferentes métodos empíricos. A comparação dos resultados obtidos pelas $\mathrm{PCE}$ e pelos métodos é apresentada na Fig. 4. Há grande divergência nos resultados para a estaca com anéis.

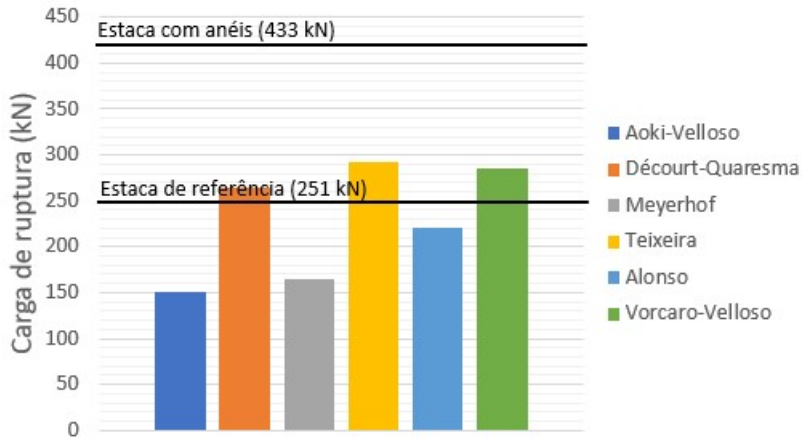

Figura 4. Métodos empíricos e resultados das PCE.

\section{Conclusões}

Os resultados obtidos permitem concluir que as estacas com anéis possuem maior capacidade de carga em relação às estacas escavadas convencionais, dada sua resistência lateral, e os métodos empíricos considerados na análise não são adequados para prever a capacidade de carga de estacas com anéis.

\section{Agradecimentos}

Agradeço ao CNPq/PIBIC pela concessão da bolsa de Iniciação Científica e ao Prof. Dr. Paulo José Rocha de Albuquerque pela orientação.

ALBUQUERQUE, P. J. R, 1996. Análise do comportamento de estaca prémoldada de pequeno diâmetro, instrumentada, em solo residual de diabásio da região de Campinas. Dissertação (Mestrado em Engenharia Agrícola) Faculdade de Engenharia Agrícola, Universidade Estadual de Campinas, Campinas. 